\title{
71. Preliminary Note on the Production of Cirrhotic Changes in the Liver by Furfural Feeding.*
}

\author{
By Waro Nakahara and Kazuo Mori. \\ Laboratories of the Japanese Foundation for Cancer Research, Tokyo.
}

(Comm. by M. NaGAYo, M.I.A., Oct. 12, 1939.)

The investigations leading to the discovery of the production of cirrhotic changes in the liver by furfural feeding, now to be briefly reported in, this preliminary note, were taken up in attempt to elucidate the prevalence of hepatoma in the Far East on the ground of the peculiarity of food and drink in that part of the world. As the starting point in that attempt we first scrutinized saké, the Japanese rice wine, and tested the effect on rats of the prolonged feeding of various known constituents of saké. Thanks to the previous investigations, especially those of Higasi, ${ }^{1}$ on the constituents of sake, it was an easy matter to select the following substances for the purpose of our experiment: Evaporated Saké solids (containing carbohydrates, amines, amino acids, etc.), acetaldehyde, furfural, methyl alcohol, ethyl alcohol, propyl alcohol, butyl alcohol, amyl alcohol, methylethyl ketone and glycerol.

Observations extending over 300 days, embracing some 700 rats, showed that under our experimental conditions none of the above listed substances, except one, produced any significant pathological change in rats. The single exception was furfural, which produced definite cirrhotic changes in the liver.

The cirrhosis producing action of furfural has now been confirmed by a second experiment, and we quote from the protocol of that experiment as follows:-

100 normal albino rats were maintained on polished rice, to which furfural was mixed evenly. The initial amount of furfural was $40 \mathrm{cc}$ per $1 \mathrm{~kg}$ of rice, but the amount was raised gradually to $100 \mathrm{cc}$ per $1 \mathrm{~kg}$ by about 2 months after the beginning of the experiment. No attempt was made to estimate the actual amount of furfural ingested by the rats as the volatility of furfural rendered any such attempt practically impossible. In view of the deficient nature of the diet, slices of fresh carrot were given to the rats from time to time.

Under the above experimental conditions 62 of the rats died during the first 37 days without showing any significant change. On the 38th day, one rat died with somewhat localized, hard and whitish areas in the liver, which proved to be cirrhotic in nature upon microscopical examination.

All other rats died since that date and the majority of them

* Aided by grants from the International Cancer Research Foundation, Philadelphia, U.S.A.

1) Higasi, T. Sci. Pap. Inst. Phys. Chem. Research, Vol. 33, 1 (1937). 
showed more or less definite cirrhotic changes, as may be seen from the following table:-

\begin{tabular}{|c|c|c|c|c|c|c|}
\hline Rat No. & $\begin{array}{l}\text { Peri } \\
\text { Sur }\end{array}$ & $\begin{array}{l}\text { d of } \\
\text { ival }\end{array}$ & $\begin{array}{l}\text { Liver } \\
\text { Findings }\end{array}$ & Rat No. & $\begin{array}{l}\text { Period of } \\
\text { Survival }\end{array}$ & $\begin{array}{l}\text { Liver } \\
\text { Findings }\end{array}$ \\
\hline 1 & 38 & lays & + & 20 & 88 days & - \\
\hline 2 & 39 & $"$ & $H$ & 21 & $" \quad n$ & $\#$ \\
\hline 3 & 40 & $"$ & - & 22 & $" \quad "$ & + \\
\hline 4 & & $"$ & - & 23 & $" \quad "$ & + \\
\hline 5 & 45 & , & + & 24 & $" \quad$, & + \\
\hline 6 & 47 & $"$ & + & 25 & $" \quad "$ & $H$ \\
\hline 7 & 50 & $"$ & + & 26 & $95 \quad$ & $H$ \\
\hline 8 & 55 & $"$ & + & 27 & $102 "$ & - \\
\hline 9 & 58 & $"$ & - & 28 & $" \quad "$ & - \\
\hline 10 & $"$ & $"$ & + & 29 & $" \quad "$ & - \\
\hline 11 & 59 & $"$ & - & 30 & $" \quad "$ & - \\
\hline 12 & 60 & $"$ & $H$ & 31 & 139, & $H$ \\
\hline 13 & 64 & $"$ & + & 32 & $142 "$ & $H$ \\
\hline 14 & 68 & $"$ & - & 33 & $149 "$ & 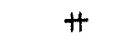 \\
\hline 15 & 69 & $"$ & $H$ & 34 & $165 \%$ & $H$ \\
\hline 16 & 85 & $"$ & + & 35 & $" \quad "$ & $H$ \\
\hline 17 & 87 & $"$ & - & 36 & $" \quad "$ & $H$ \\
\hline 18 & 88 & $"$ & - & 37 & 167, & $H$ \\
\hline 19 & & $"$ & $H$ & & & \\
\hline
\end{tabular}

The cirrhotic changes in question manifested themselves usually as somewhat localized hard and whitish areas with granular and uneven surface. These conspicuous changes most frequently involved the entire caudate lobe, and also frequently occurred in the basal portions of other lobes. In the more advanced cases, the cirrhotic changes were found to involve more or less the entire organ, the appearance of which then closely resembling that of the typical atrophic cirrhosis. In the above table the positive findings were classed into + or $\#$ according to the degrees of the generalization of the cirrhotic changes. The minus sign $(-)$ in the table does not mean that the liver was normal ; it only indicates that no gross cirrhotic change was noted. Organs other than the liver showed no significant change, and, in special, there was no splenic tumor in any of the rats.

Histologically, the characteristic liver lesion was found to consist of marked fibrosis, often occupying a considerable area, usually in an obvious association with the interlobular vein. Within the fibrous areas were found many duct-like structures, presumably formed through the tubular metaplasia of liver cells rather than the proliferation of bile ducts. In some cases, these so-called pseudo-bile ducts were undergoing enlargement and proliferation.

Earlier changes apparently began as the proliferation of young 
connective tissue and round cell infiltration in Glisson's capsules, which, through extension and coalescence progressively surrounded and later invaded the liver acinus. Thus, the general histological character of the change resembled atrophic or annular cirrhosis.

In another experiment the amount of furfural was reduced to $10-40 \mathrm{cc}$ per $1 \mathrm{~kg}$ of rice. This greatly prolonged the time required for the production of cirrhotic change, $(200 \sim 500$ days $)$. Similar cirrhotic change can be produced by furfural feeding also in guineapigs and rabbits, and we already obtained a few positive cases. Extensive further experiments on the production of liver cirrhosis by furfural feeding are now under way in this laboratory, and the results will be reported elsewhere in full when the experiments are completed.

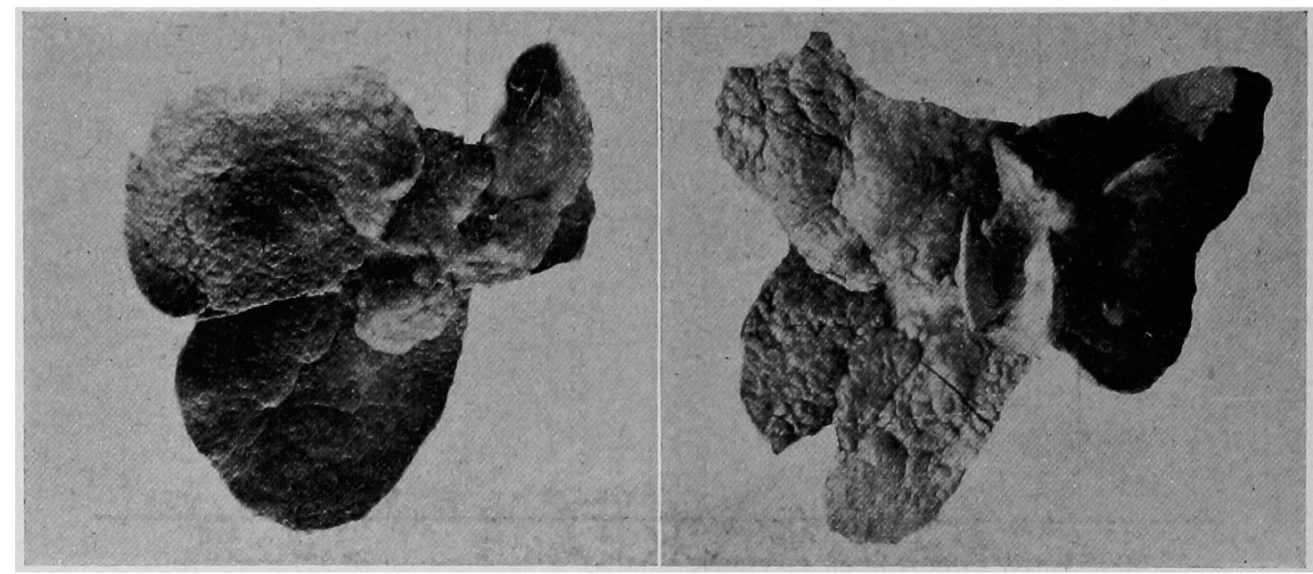

Fig. 1. Two examples of the cirrhotic liver (Rats 12 and 33, fed with furfural for 60 and 145 days, respectively).

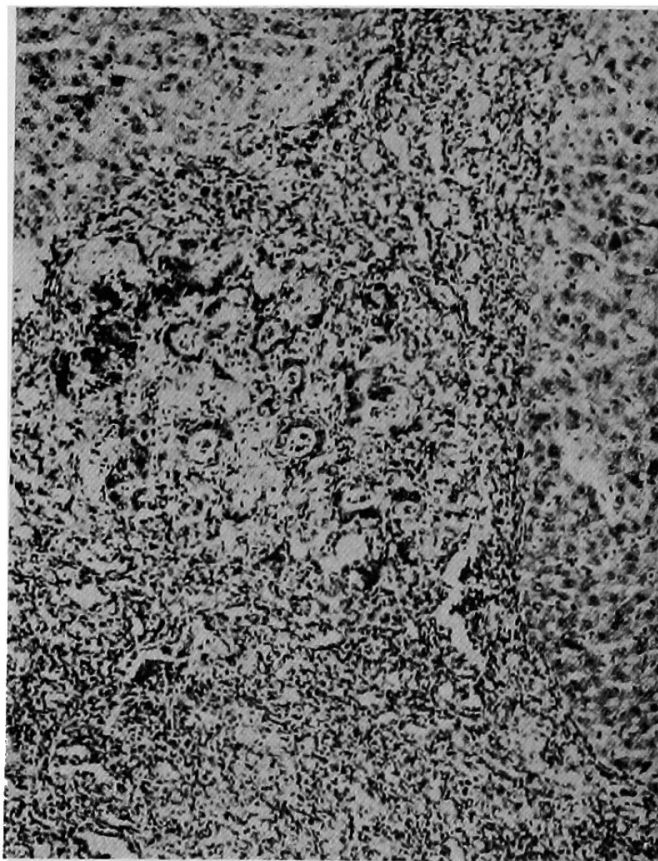

Fig. 2. Typical cirrhotic area of the liver, showing numerous pseudo-bile ducts.

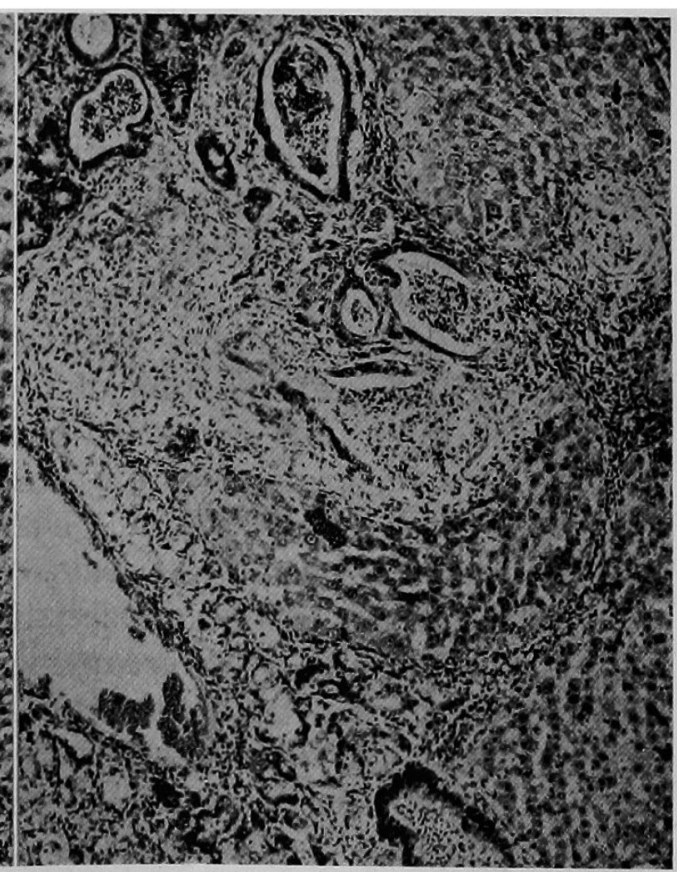

Fig. 3. Enlargement and proliferation of pseudo-bile ducts in cirrhotic area. 


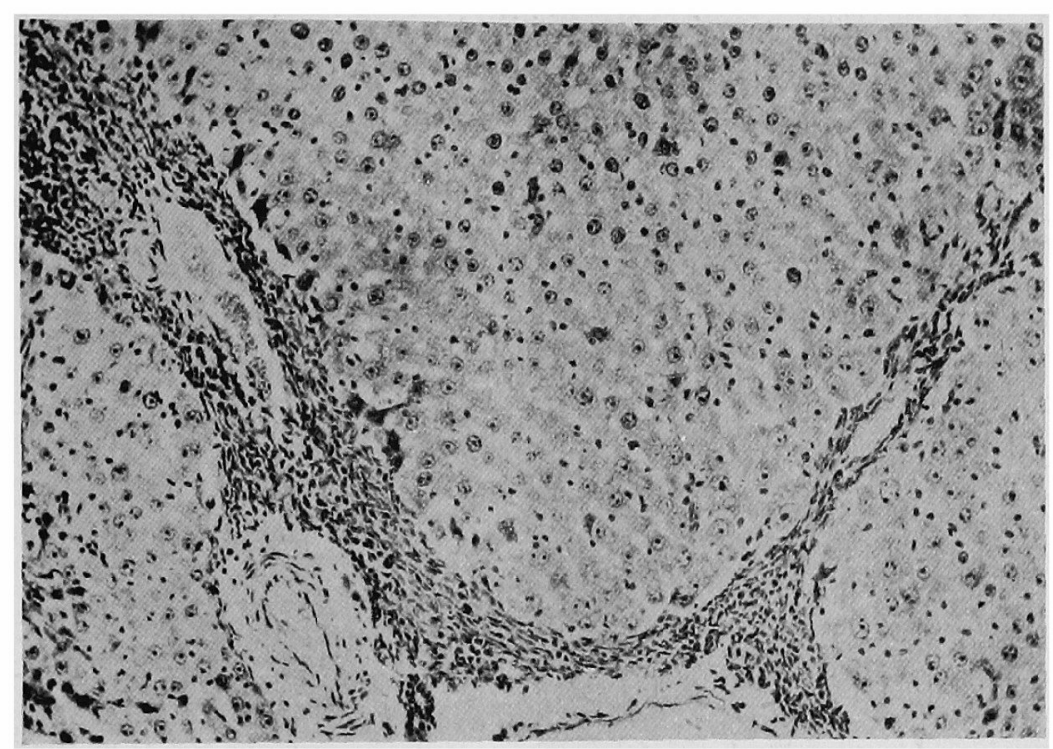

Fig. 4. Earlier cirrhotic change consisting of the proliferation of young connective tissue in Glisson's capsule. 